\title{
A educação integral: a escola como direito na perspectiva da humanização e da cidadania
}

Maria Cristiani Gonçalves Silva ${ }^{1}$

\section{Resumo}

Apresenta os fundamentos históricos do conceito de Educação Integral e do alcance dessa expressão na Filosofia da Educação e na dimensão política do termo. Debate as questões de Educação de Tempo Integral analisando as teorias e práticas de ampliação de jornadas na organização da Educação e da Escola no Brasil, decorrente dos modelos ocidentais. Apresenta as principais experiências de Educação Integral e de organização de Escolas de Tempo Integral no Brasil e explora suas originalidades, suas características e suas contradições. Apresenta a possibilidade de uma política de Educação Integral em Escolas de Tempo Integral a partir da concepção da Educação como Direito ou do Direito à Educação, contextualizando tal possibilidade no ciclo de atuação política aberto pela eleição de Luis Inácio Lula da Silva e Dilma Rousself na política brasileira. Destaca as novas ordenações jurídicas da sociedade brasileira e aponta para a possibilidade de uma Nova Educação Integral.

Palavras-chave: Educação integral. Filosofia. Emancipação. Ética.

\section{Resumen}

Presenta los fundamentos historicos del concepto de Educación Integral y del alcance de esa expresión en la Filosofía de la Educación y en la dimensión política del término. Debate las cuestiones de Educación de Tiempo Integral analizando las teorías y prácticas de ampliación de jornadas en la organización de la Educación y la Escuela en Brasil, derivada de los modelos occidentales. Presenta las principales experiencias de Educación Integral y de organización de Escuelas de Tiempo Integral en Brasil y explora sus originalidades, sus características y suyas contradicciones. En el marco de la política de educación integral en las escuelas de tiempo completo a partir de la concepción de la Educación como Derecho o del Derecho a la Educación, contextualizando tal posibilidad en el ciclo de actuación política abierto por la elección de Luis Inacio Lula da Silva y Dilma Rousself en la política brasileño. Destaca las nuevas ordenaciones jurídicas de la sociedad brasileña y apunta a la posibilidad de una nueva Educación Integral.

Palabras-clave: Educación integral. Filosofía. Emancipación. Ética.

\footnotetext{
${ }^{1}$ Pesquisadora do Grupo de pesquisa PAIDEIA-UNICAMP/CAPES. E-mail: mariacristianigsilva@gmail.com
} 


\section{Introdução}

$\mathrm{P}$ retendemos com o presente texto discutir as possíveis conexões entre a proposta de Educação Integral, debatida no Brasil nos anos recentes, e a questão dos direitos sociais e o dos direitos humanos. Esse artigo é resultado de parte de nossa pesquisa de doutoramento desenvolvida junto ao Grupo de pesquisas PAIDEIA, da Faculdade de Educação - UNICAMP. De cunho histórico-filosófico e de fundamentação crítico-dialética e materialista, nosso aporte para tal discussão se dará a partir dos marcos legais brasileiros e de fontes bibliográficas que permeiam a proposta da Educação Integral e da Escola em Tempo Integral atualmente em construção, no país.

Entendemos que, como premissa teórico-política, não há como reconhecer a possibilidade de efetivar mudanças na esfera da escola e da educação se não houver igualmente um processo de transformações e de mudanças na dinâmica das relações sociais, isto é, na organicidade da prática social. As mudanças e transformações que se efetivam na educação e na escola são resultantes de transformações, enfrentamentos, lutas e conquisas que se travam na dialética da vida política e no campo da luta social.

Zucchetti e Moura (2017) afirmam que, embora a questão em torno dos direitos à proteção social, à saúde e à educação seja relativamente nova no Brasil, o substrato que as fundamenta não é uma novidade inventada pela Modernidade. Certa noção de direitos humanos já estava presente nos debates da Antiguidade e, ao longo da história do Ocidente, vem ocupando o centro de inúmeras lutas por direitos sociais, oriundas das contradições da sociedade e de seus movimentos.

\section{A Educação Integral: fundamentos.}

É no século XX que a noção de direitos humanos tornou-se a principal referência a nortear a vida em sociedade e, mais do que isso, tornou-se a principal inspiração para a ação dos Estados definidos como 
democráticos, no sentido de garantir a igualdade de oportunidades a todos os cidadãos e cidadãs, nos domínios da esfera pública estatal e não-estatal. Longe do êxito obtido pelos países europeus no que tange à materialidade das ações implementadas no campo dos direitos humanos - por meio da constituição de um Estado de Bem-Estar - no Brasil, os direitos sociais situam-se no bojo de lutas e enfrentamentos constantes. Tomam feições de leis afirmativas materializadas por seus programas/projetos de inclusão social que são oferecidas pelas esferas do poder estatal e, também, pela sociedade civil organizada. Estão voltadas para os segmentos sociais mais afetos a uma sociedade vulnerabilizadora e, em geral, manifestam-se enquanto medidas de proteção (social) no amparo às necessidades básicas (Zucchetti e Moura, 2017).

Presente no cenário brasileiro desde o começo do século $\mathrm{XX}$, a educação integral vem ganhando cada vez mais importância no debate público nacional, principalmente no contexto de início de vigência da política educacional preconizada pelo Plano Nacional de Educação (PNE). A educação integral busca garantir o pleno desenvolvimento de crianças, adolescentes e jovens, propiciando múltiplas oportunidades de aprendizagem por meio da ampliação do tempo e do acesso à cultura, arte, esporte, ciência e tecnologias, entre outros. Ao longo da história as experiências de educação integral no Brasil tem apresentado uma forte característica assistencialista, que busca atender as comunidades mais vulneráveis e economicamente excluídas, exercendo um papel de promover o pleno direito de formação escolar para tal parcela da sociedade. Alguns críticos diriam que tais programas visavam atingir um papel social reparador e assistencialista.

A educação integral se baseia na concepção de um desenvolvimento pleno do ser humano e reconhece que esse desenvolvimento só é possível quando se considera que os processos de aprendizagem ocorrem de modo multidimensional - física, afetiva, cognitiva, ética, estética e política - e se articulam os diversos saberes da escola, da família, da comunidade e da região em que o indivíduo se insere. 
Atualmente diversas prefeituras e estados têm experiências de escola em tempo integral, na medida em que seus fundamentos e regulamentações encontram-se previstos no Plano Nacional de Educação (PNE) e, consequentemente, nos Planos Municipais (PMEs) e Estaduais de Educação (PEEs). Tais experiências se intensificaram na última década devido à criação do PME - Programa Mais Educação em 2007.

O Programa é uma iniciativa que surge a partir da Portaria Normativa Interministerial $\mathrm{n}^{\circ} 17$, de 24 de abril de 2007, regulamentada pelo Decreto $\mathrm{n}^{\mathrm{o}} 7.083$, de 27 de janeiro de 2010, e integra as ações do Plano de Desenvolvimento da Educação (PDE) ${ }^{2}$. Programa este que teve o mérito de dialogar com ações empreendidas não apenas pelo MEC - Ministério da Educação, mas também pelos Ministérios da Cultura, do Esporte, do Meio Ambiente, do Desenvolvimento Social e Combate à Fome, da Ciência e Tecnologia e pela Secretaria Nacional de Juventude, em uma perspectiva intersetorial. Em 2010, passou a contar com o apoio também do Ministério da Defesa.

A proposta inclui fundamentos da educação integral e se propõe a induzir e estimular o surgimento de políticas públicas nesse sentido em todo o país, nos diferentes entes responsáveis pela educação pública. "O Mais Educação foi pensado como uma política indutora de extensão de jornada para, no mínimo, sete horas diárias e para a formação integrada", diz Jaqueline Moll (2013), uma das criadoras do programa.

Ao longo da construção da política pública de educação integral no Brasil, observamos a insistente presença de uma confusão conceitual entre ampliação da jornada escolar com educação integral; em sua maioria, os responsáveis pela pasta da educação pública cometem esse engano ou confusão ao construírem seus projetos pedagógicos ou planos de educação, na perspectiva de que basta ampliar a jornada para se fazer educação integral.

\footnotetext{
${ }^{2}$ PDE - O Plano de Desenvolvimento da Escola (PDE-Escola) auxilia a escola pública, pois trata-se de planejamento estratégico em que a escola investe em sua qualificação para oferecer mais qualidade de ensino ao estudante, aumentando a aprendizagem escolar. $\mathrm{O}$ PDE-Escola auxilia as equipes a trabalhar com os mesmos objetivos e em busca de resultados comuns, reconhecendo que os ambientes sociais estão em constante mudança.
} 
Nesse contexto, Miguel Arroyo chama a atenção quando defende Educação Integral como uma elevação da "consciência política de que ao Estado e aos governantes cabe o dever de garantir mais tempo de formação, de articular os tempos-espaços de seu viver, de socialização". Ao mesmo tempo, o autor alerta para os riscos de uma Educação Integral, de baixa potência, ao afirmar que: “[...] uma forma de perder seu significado político será limitar-nos a oferecer mais tempo da mesma escola, ou mais um turno turno extra - ou mais educação do mesmo tipo de educação" (Arroyo, 2012, p. 33).

Programas de Educação Integral encontram apoio na legislação brasileira, já que o direito ao pleno desenvolvimento das pessoas está pressuposto nos principais marcos legais educacionais do país. Paralelamente, municípios e estados vêm estruturando mecanismos jurídicos - buscando a aprovação de leis locais - que amparem a criação de uma política pública de educação integral.

Apresentando estes esclarecimentos de base sobre o PME, no âmbito deste texto, buscaremos refletir a partir de uma análise histórico-dialética, sobre os pressupostos presentes numa proposta de educação integral ensejando examinar a noção de direitos humanos articulada à educação, enquanto direito social e consubstanciada na doutrina da formação integral, presente nesta modalidade educativa. Discussão que nos é permitida realizar a partir de investigações bibliográficas sobre a práxis educativa, as avaliações e análises de programas que visavam e visam à educação integral.

Ao longo do século XX, as nações envolveram-se em duas guerras mundiais e assistiram à eclosão de diversas crises econômicas, responsáveis pelo aprofundamento das desigualdades e injustiças sociais. Ainda em meados do mesmo século, paralelamente à instauração do Estado de BemEstar Social, ressurgiu com força no solo europeu a ideologia liberal trazendo sérias restrições às conquistas relacionadas aos direitos sociais, minando os valores da democracia e alavancando o crescimento da exclusão social, num movimento que ficou conhecido como ressurgimento neoliberal 
ou neoliberalismo. Fatos que serviram para reafirmar a noção de direitos humanos como sendo a base de manifestações e lutas por igualdade social e paz mundial.

Neste contexto, mesmo que não logrando o mesmo resultado que obtiveram os países europeus no que tange à implantação do Estado de Bem-Estar Social, no Brasil, desde a década de 1980, é possível mencionar um conjunto de articulações que resultaram em manifestações em favor do direito de igualdade. As passeatas em defesa da educação pública, contra a exploração do trabalho infantil, contra a pedofilia, passando pela luta em reconhecimento dos direitos dos povos indígenas, incluindo os direitos civis dos homossexuais, das mulheres até as recentes manifestações dos jovens o chamado outono brasileiro - são expressões da vontade popular. Também a luta pela democratização da educação, pela reforma agrária, assim como, os movimentos grevistas protagonizados por inúmeras categorias profissionais na década de 1980, são outros exemplos ilustrativos do desejo de transformações que tomou conta do Brasil a partir da segunda metade do século XX e que se apoiam na noção de direitos humanos, como um direito fundamental. Lutas essas que se mantiveram ao longo das últimas décadas do referido século, se tornaram mais amenas durante a primeira década do século XXI e, atualmente organizações sociais, sindicais e o cidadão comum voltam às ruas lutar contra a perda de direitos e contra a exposição da corrupção que assola os poderes constituídos no país.

Após a abertura para a democratização, efetivada na década de 1980, grandes lutas sociais foram travadas na busca da garantia de direitos no Brasil, principalmente para os grupos mais vulneráveis e excluídos historicamente de nossa sociedade. A partir da Constituição Federal de1988, encontramos possibilidades legais para a construção de uma sociedade mais inclusiva, humana e cidadã.

\section{Uma nova Educação Integral.}

Arroyo (2013) vai nos chamar atenção para os novos sujeitos que adentram nossas escolas, afirma que são filhos dos movimentos sociais que, 
historicamente, lutam pela garantia de direitos, por uma educação pública de qualidade, por terra, por teto, por saúde, por transporte e segurança, lutam pelas mulheres, pelas crianças, pelos idosos, pelos homoafetivos, lutam pela defesa do meio ambiente e pela sustentabilidade, e lutam contra o preconceito, a exploração, a exclusão. São essas lutas travadas por coletivos dos mais diversos segmentos que nos propiciou esse ganho legal para o cidadão brasileiro.

No que tange à tais direitos e à educação integral, faremos uma breve exposição do marcos legais que visam garantir direitos aos cidadãos brasileiros a fim de buscar relacioná-los com a educação integral, visando constituir uma sociedade de novos sujeitos sociais, centrada no reconhecimento de uma cidadania sobre direitos.

Na Constituição Federal de 1988, tal discussão é apresentada de modo "subliminar" sendo "deduzida" a partir da conjugação de: i) a educação como primeiro dos dez direitos sociais (art.6); ii) "como direito capaz de conduzir ao 'pleno desenvolvimento da pessoa, fundante da cidadania, além de possibilitar a preparação para o mundo do trabalho’ (art. 205), (Menezes, 2009 p. 70). É nesse quadro hipotético que Menezes (2009) afirma o direito de todos ao que denomina de educação integral ou a uma educação portadora de diversas funções.

A partir da Constituição Federal produzimos outros dispositivos legais que possibilitam a construção de uma educação integral humanizadora e inclusiva, dentre elas podemos citar: O Estatuto da Criança e do Adolescente (ECA) - Lei 8.069 de 13 julho de 1990 - que afirma no Capítulo V:

\footnotetext{
Art. 53. A criança e o adolescente têm direito à educação, visando ao pleno desenvolvimento de sua pessoa, preparo para o exercício da cidadania e qualificação para o trabalho, assegurando-se-lhes:

I - igualdade de condições para o acesso e permanência na escola;

II - direito de ser respeitado por seus educadores;

III - direito de contestar critérios avaliativos, podendo recorrer às instâncias escolares superiores;

IV - direito de organização e participação em entidades estudantis;

V - acesso à escola pública e gratuita próxima de sua residência.
} 
Dentro do espectro legal, podemos citar também, a Lei de Diretrizes e Bases (LDB - Lei 9.394/1996): no ensino fundamental, ela articula o artigo 2, especificamente quando este menciona o "pleno desenvolvimento do educando" - reiterando o princípio defendido acima, presente na constituição federal - com os artigos 34 em seu parágrafo $2^{\circ}$ e 87 em seu $5^{\circ}$ parágrafo. Ambos os artigos versam sobre a progressiva ampliação do tempo escolar, ficando este a critério dos estabelecimentos de ensino. Esta relação não especifica como tal jornada será ampliada; no entanto, o artigo 3, em seus incisos X e XI, nos fornecem algumas pistas, respectivamente: "Valorização da experiência extraescolar"; "Vinculação entre a educação escolar, o trabalho e as práticas sociais".

Outro dispositivo legal que produzimos, trata-se da Lei Maria da Penha que visa coibir a violência contra a mulher - Lei 11.340 de 7 de agosto de 2006 - cujo artigo $1^{\circ}$ segue na integra:

\begin{abstract}
Art. 1o Esta Lei cria mecanismos para coibir e prevenir a violência doméstica e familiar contra a mulher, nos termos do $\S 8$ o do art. 226 da Constituição Federal, da Convenção sobre a Eliminação de Todas as Formas de Violência contra a Mulher, da Convenção Interamericana para Prevenir, Punir e Erradicar a Violência contra a Mulher e de outros tratados internacionais ratificados pela República Federativa do Brasil; dispõe sobre a criação dos Juizados de Violência Doméstica e Familiar contra a Mulher; e estabelece medidas de assistência e proteção às mulheres em situação de violência doméstica e familiar.
\end{abstract}

A presente lei contribui, para além da violência física, pensarmos sobre a condição da mulher no Brasil, ainda definida como inferiorizada e violentada, pois vivemos numa sociedade historicamente patriarcal e machista, colonizada por um conceito de mulher como mercadoria, através das propagandas, da sensualização e erotização do corpo da mulher, através da mercantilização do sexo, através da música, tidas de baixo nível que prevalece na indústria cultural, que vulgariza, inferioriza, sexualiza, erotiza a mulher, tudo isso expressa uma condição banalizada e vil sobre a mulher na sociedade (Nunes, 1987). 
Vivemos em país historicamente escravocrata, visto que, ao receber a carta de alforria, o povo negro foi jogado às margens da sociedade: sem teto, sem escola, sem trabalho, sem direitos. Ainda hoje, a consequência dessa escravização é visível, e parcela de nossa sociedade ainda vive às margens e sofre preconceito de raça, Em2003 foi apresentado na Câmara dos Deputados o projeto de Lei para tratar da igualdade racial. Após 7 anos de discussão e adaptação do texto, foi criado o Estatuto da Igualdade Racial - Lei 12.288 de 20 de julho de 2010 - que foi instituída depois de mais de um século de luta pela igualdade racial, segue trecho:

Art. 1o Esta Lei institui o Estatuto da Igualdade Racial, destinado a garantir à população negra a efetivação da igualdade de oportunidades, a defesa dos direitos étnicos individuais, coletivos e difusos e o combate à discriminação e às demais formas de intolerância étnica.

Nossa sociedade elitista, cordial, meritocrática ainda não quebrou esse paradigma na produção de uma cultura de igualdade racial no Brasil. Tanto que atualmente entrou em vigor está a Lei das Cotas - Lei 12.711, 29 de agosto de 2012 - visando mudanças significativas na democratização do acesso ao ensino superior e na redução da desigualdade social no país. Mesmo polêmica, a lei avança com negros, indígenas e pardos circulando nos campos universitários, ação afirmativa com foco social, étnico e retração histórica.

As lutas e movimentos sociais conquistaram também as Diretrizes Curriculares Nacionais para a Educação Ambiental - CNE/CP nº 2/2012, de 18 de junho de 2012 - a qual define que a educação para a cidadania compreende a dimensão política do cuidado com o meio ambiente local, regional e global. O atributo "ambiental” na tradição da Educação Ambiental brasileira e latinoamericana não é empregado para especificar um tipo de educação, mas se constitui em elemento estruturante que demarca um campo político de valores e práticas, mobilizando atores sociais comprometidos com a prática político-pedagógica transformadora e emancipatória capaz de promover a ética e a cidadania ambiental. 
Nesse contexto, foi aprovado, em 2014, o Plano Nacional de Educação (PNE), que procura orientar as políticas de educação brasileiras para os próximos dez anos. Pela primeira vez na história tivemos uma lei educacional escrita por milhares de mãos poderíamos dizer, tal projeto de lei surgiu da sociedade civil organizada após conferências regionais, estaduais e nacional, sendo protocolado na Câmara dos Deputados, onde sofreu algumas modificações, porém, muito da vontade da sociedade civil foi mantida após a aprovação da lei.

Uma das metas do PNE aborda a questão da ampliação do tempo de permanência dos estudantes na escola. A meta 6 estipula que "A educação brasileira deve oferecer nos próximos 10 anos educação em tempo integral em, no mínimo, $50 \%$ das escolas públicas, de forma a atender, pelo menos, $25 \%$ de matrículas da Educação Básica".

Uma das constatações que fazemos, no âmago dessa conjuntura, é que as lutas e conquistas legais configuram somente um passo para a transformação profunda das características estruturais da sociedade e da educação no Brasil. O enquadramento de direitos na esfera legal é uma etapa dessa luta. A segunda medida, decorrente dessa, consiste em buscar transformar os direitos legais, duramente conquistados, em prática política real, logra transformar os direitos proclamados em prática social. (NUNES, 2013)

Com o impeachment da Presidenta Dilma Rousself em 2016, o novo governo tido por muitos como ilegítimo, o Presidente Michel Temer inicia a desconfiguração do Programa Mais Educação, institui nova portaria que cria PNME - Programa Novo Mais Educação, Portaria n 1.144, de 10 de outubro de 2016. O Programa visa à ampliação da jornada escolar de crianças e adolescentes, mediante a complementação da carga horária de cinco ou quinze horas semanais no turno e contra turno escolar, que deverá ser implementado por meio da realização de acompanhamento pedagógico, obrigatório, em língua portuguesa e matemática e, no caso da jornada integral, do desenvolvimento e atividades no campo das artes, cultura, esporte e lazer. 
Jaqueline Moll (2016) na sua intervenção no Seminário O Direito à Educação Integral: rupturas e resistências, em Outubro de 2016, na Faculdade de Educação da UFMG, afirma que tal reestruturação do programa - o Novo Mais Educação - não corresponde mais aos ideais da educação integral. É uma abordagem diferente, que se foca em "reforço escolar", com ênfase em matérias como português e matemática, o que é exatamente o tipo de prática engessada que o programa original buscava evitar.

Somando aos direitos conquistados, temos o Estatuto da Pessoa com Deficiência - Lei 13.146 de 6 de julho de 2015 - destinado a assegurar e a promover, em condições de igualdade, o exercício dos direitos e das liberdades fundamentais por pessoa com deficiência, visando à sua inclusão social e cidadania é mais uma conquista. Após anos de lutas pela inclusão das pessoas com deficiência, hoje já temos a essa garantia.

Por fim, na busca de reconhecer os direitos dos travestis e transexuais e reconhecer sua identidade, temos o Decreto 8.727, de 28 de abril de 2016 que dispõe sobre o uso do nome social e o reconhecimento da identidade de gênero de pessoas travestis e da administração pública federal direta. Segue trecho inicial do decreto:

Art. 1o Este Decreto dispõe sobre o uso do nome social e o reconhecimento da identidade de gênero de pessoas travestis ou transexuais no âmbito da administração pública federal direta, autárquica e fundacional.

Parágrafo único. Para os fins deste Decreto, considerase:

I - nome social - designação pela qual a pessoa travesti ou transexual se identifica e é socialmente reconhecida; $\mathrm{e}$

II - identidade de gênero - dimensão da identidade de uma pessoa que diz respeito à forma como se relaciona com as representações de masculinidade e feminilidade e como isso se traduz em sua prática social, sem guardar relação necessária com o sexo atribuído no nascimento.

$\mathrm{O}$ conceito de gênero está baseado em parâmetros científicos de produção de saberes sobre o mundo e busca identificar processos históricos e culturais que classificam as pessoas a partir de uma relação sobre o que é entendido como feminino e masculino. O século $\mathrm{XX}$ e essas décadas 
recentes viram avançar o reconhecimento sobre a plenitude da condição humana e sua efetiva diversidade.

Todas essas conquistas se encontram sistematizadas nas Diretrizes Curriculares da Educação Básica Nacional de 2014. A necessidade da atualização das Diretrizes Curriculares Nacionais surgiu da constatação de que as várias modificações - como o Ensino Fundamental de nove anos e a obrigatoriedade do ensino gratuito dos quatro aos 17 anos de idade deixaram as anteriores defasadas. Estas mudanças ampliaram consideravelmente os direitos à educação das nossas crianças e adolescentes e também de todos aqueles que não tiveram oportunidade de estudar quando estavam nessa fase da vida.

\section{Considerações Finais}

Diante dessa nova realidade e em busca de subsídios para a formulação de Novas Diretrizes Curriculares Nacionais, a Câmara da Educação Básica do Conselho Nacional de Educação promoveu uma série de estudos, debates e audiências públicas, com a anuência e participação das entidades representativas dos dirigentes estaduais e municipais, professores e demais profissionais da educação, instituições de formação de professores, mantenedoras do ensino privado e de pesquisadores da área.

As Novas Diretrizes Curriculares da Educação Básica buscam prover os sistemas educativos em seus vários níveis (municipal, estadual e federal) de instrumentos para que crianças, adolescentes, jovens e adultos que ainda não tiveram a oportunidade, possam se desenvolver plenamente, recebendo uma formação de qualidade correspondente à sua idade e nível de aprendizagem, respeitando suas diferentes condições sociais, culturais, emocionais, físicas e étnicas.

É por isto que, além das Diretrizes Gerais para Educação Básica e das suas respectivas etapas, quais sejam, a Educação Infantil, Fundamental e Média, também integram a obra as diretrizes e respectivas resoluções para a Educação no Campo, para a Educação Indígena, para a Comunidade Quilombola, para a Educação Especial, para Jovens e Adultos em Situação 
de Privação de Liberdade nos estabelecimentos penais e para a Educação Profissional Técnica de Nível Médio. Além disso, aqui estão presentes as diretrizes curriculares nacionais para a Educação de Jovens e Adultos, a Educação Ambiental, a Educação em Direitos Humanos e para a Educação das Relações Étnico-Raciais e para o Ensino de História e Cultura AfroBrasileira e Africana.

Isto posta, sabemos que novos sujeitos emergem desta cultura de resistência e refundação de nossa sociedade, da qual somos herdeiros de sentimentos socialmente valorados, marcados pela competição, pelo egoísmo, pela ganância, pela exposição banal da sexualidade, pela exploração do trabalho, pela superficialidade das palavras e pela falência dos acordos coletivos, por isso não basta termos dispositivos legais que apontem e garantam os direitos para esse novo sujeito, precisamos de uma novíssima escola para quebrar esse estigma social, precisamos de uma novíssima escola para transformarmos nossas práticas educativas reprodutoras em práticas educativas transformadoras, humanizadoras e democráticas (Nunes, 2013).

Nessa constatação, estamos convencidos de que, na conjuntura de refluxo ou de regressão que assistimos hoje, no âmbito do Estado, tomado de maneira ilegítima, a tarefa mais importante é manter a lucidez e reencetar a dinâmica da luta, em todos os campos, de modo a denunciar o arbítrio e convencer ou ressensibilizar as forças e movimentos sociais, para a necessidade de novas práticas de esclarecimento político e de determinação ativa.

\section{Referências}

ARROYO, M. Outros Sujeitos, Outras Pedagogias, Petrópolis, RJ: Vozes, 2012.

ARROYO, M. Pedagogias do movimento: o que temos a aprender dos movimentos sociais? Currículo sem fronteiras, v.3, $\mathrm{n}^{\circ}$ 1, p. 28-49, jan/jun, 2003. 
ARroYO, Miguel G. O Direito ao Tempo de Escola. UFMG. Caderno de Pesquisa, São Paulo (65): 3-10, maio, 1988.

BRASIL, Constituição da República Federativa do Brasil. Brasilia, 1988.

BRASIL, Estatuto da Criança e do Adolescente. Lei 8.069. Brasília, 1990.

BRASIL, Ministério da Educação. Lei no 9.394/96, de Diretrizes e Bases da Educação Nacional (LDBEN). Brasília, 1996.

BRASIL. Lei Maria da Penha. Lei N. ${ }^{\circ} 11.340$. Brasilia, 2006.

BRASIL, Ministério da Educação. Manual Mais Educação: passo a passo. Brasília, 2008.

BRASIL, Estatuto da Igualdade Racial. Lei no 12.228. Brasilia, 2010.

BRASIL, Ministério da Educação. Conselho Nacional de Educação/Conselho Pleno. Resolução no 2, de 15 de junho de 2012. Diretrizes Curriculares Nacionais para a Educação Ambiental. Brasília, 2012.

BRASIL, Lei no 13.005/2014. Plano Nacional de Educação (PNE) 2. ed. Brasília: Câmara dos Deputados, Edição Câmara, 2015.

BRASIL. Lei n 13.146/2015. Lei Brasileira de Inclusão da Pessoa com Deficiência. Brasilia, 2015.

BRASIL. Decreto $\mathbf{n}^{\circ}$ 8727. Presidência da República. Casa Civil. Disponível em <http://www.planalto.gov.br/ccivil_03/_Ato20152018/2016/Decreto/D8727.htm> Acesso em 11 mai. 2017. 
CAVALIERI, Ana Maria Villela. Educação escolar e atenção integral à criança e ao Adolescente. In: Subsídios para uma proposta de atenção integral à criança em sua dimensão pedagógica. Cadernos de Educação Básica. Série Institucional, n 3. p. 9-26. Brasília: Ministério da Educação e do Desporto. Secretaria de Educação Fundamental, 1994.

COELHO, Ligia Martha Coimbra Costa, CAVALIERE, Ana Maria Villela (orgs). Educação brasileira e(m) tempo integral. Petrópolis: Vozes, 2002.

COELHO, Ligia Martha Coimbra Costa (org). Educação integral em tempo integral: estudos e experiências em processo. Petrópolis: DP ET Alii: Rio de Janeiro: FAPERJ, 2009.

GALLO, Silvio. A educação integral numa perspectiva anarquista. In: COELHO, Lígia Martha Coimbra da Costa; CAVALIERE, Ana Maria Villela (Org.). Educação Brasileira e(m) tempo integral. Petrópolis, RJ: Vozes, 2002.

GRAMSCI, Antonio. Concepção dialética da história. Rio de Janeiro: Civilização Brasileira, 1978.

GRAMSCI, Antonio. Os intelectuais e a organização da cultura. Rio de Janeiro, Civilização Brasileira, 1968.

MAURÍCIO, Lucia Veloso. Escritos, representações e pressupostos da escola pública de horário integral. In MAURÍCIO, Lucia Velloso (org): Em aberto: educação integral em tempo integral. v. 22, n. 80, p. 1-165, abr. 2009.

MENEZES, Janaina Specth. Educação integral \& tempo integral na educação básica. In: COELHO, Ligia Martha C. C. (org.). Educação integral em tempo integral: estudos e experiências em processo. Petrópolis-RJ: DP et alli. Rio de Janeiro: Faperj, 2009. 
MOLL, Jaqueline (org.). Caminhos da educação integral no Brasil: direitos a outros tempos e espaços educativos. Porto Alegre: Penso, 2012.

MOLL, Jaqueline. Ciclos na Escola, tempos na vida: criando possibilidades. Porto Alegre: ARTMED, 2004.

MOLL, Jaqueline. Histórias de vida, histórias de escola: elementos para uma pedagogia da cidade. Petrópolis: Vozes, 2000.

MOLL, Jaqueline. Um paradigma contemporâneo para a educação integral. Revista Pátio. Ano XIII n 51. p. 13 - 15. São Paulo: Artmed, 2009.

NOSELLA, Paolo. A escola de Gramsci. São Paulo: Cortes, 2004.

NUNES, Cesar Aparecido, Aprendendo Filosofia/ César Aparecido Nunes2. ed. - Campinas, SP: Papirus, 1987. (Coleção Educar Aprendendo - Série Educando).

NUNES, Cesar Aparecido, Desvendando a Sexualidade. 5.ed. Campinas: Papirus, 1987.

NUNES, Cesar Aparecido. Educar para a emancipação. Florianópolis, SC: Sophos, 2003.

NUNES, Cesar Aparecido. Educação, Pedagogia e Sociedade: matrizes políticas e estigmas culturais da instituição escolar no Brasil. In: ROMÃO, Lucília M. S. (Org.). Leitura, História e Educação: um diálogo possível. Ribeirão Preto, SP: Alphabeto Editora, 2006.

NUNES, Cesar Aparecido. Educação, Docência e Memória: desa(fios) de professores/Eliana Sampaio Romão, César Nunes, José Ricardo Carvalho (Org.), A educação brasileira, as novas diretrizes curriculares e a 
formação dos professores. Eliane Francisco dos Santos. [et al.]... Campinas, SP: Librum Editora, 2013.

PARO, Vitor Henrique et al. A escola pública de tempo integral: universalização do ensino e problemas sociais. Cadernos de Pesquisa, São Paulo, n. 65, p. 11-20, maio 1988a.

PARO, Vitor Henrique et al. Escola de Tempo Integral: desafio para o ensino público. São Paulo, Cortez: Autores Associados, 1988b.

SAVIANI, Demerval. Educação: Do Senso Comum a Consciência Filosófica. São Paulo, Cortez, 1986.

SAVIANI, Demerval. Pedagogia Histórico-crítica: primeiras aproximações; São Paulo: Autores Associados, v. 40, 1991.

SAVIANI, Demerval. et. al. O Legado Educacional do Século XX no Brasil. Campinas; Autores Associados, 2004.

SAVIANI, Demerval. O Plano de Desenvolvimento da Educação: análise do projeto do MEC. Educ. Soc., Campinas, vol. 28, n.100 - Especial, p. 12311255, out. 2007. Disponível em http://www.cedes.unicamp.br

SAVIANI, Demerval. Pedagogia Histórico-crítica. São Paulo: Autores Associados, 2008.

SAVIANI, Demerval. Sistema Nacional de Educação articulado ao Plano Nacional de Educação. Revista Brasileira de Educação, v. 15, n. 44, maio/ago. 2010.

SILVA, Maria Cristiani G. Os Pressupostos Filosóficos Da Educação Cooperativista No Estado De São Paulo (1989 - 2011): Matrizes 
Pedagógicas e contradições institucionais e políticas. Dissertação Mestrado.

Faculdade Educação Universidade Estadual de Campinas. UNICAMP, 2012.

ZUCCHETTI, D.T. MOURA, E. P. G, Ensaio: aval. Políticas públicas Educacionais, Rio de Janeiro, v.25, n. 94, p. 257-276, jan./mar. 2017. 